\title{
Grinding of Maraging Steel 1.2709 with SiC Grinding Wheels and Effect of Grin- ding Conditions on the Surface Roughness and Wear of the Wheels
}

Jindrich Farsky, Tomas Baksa, Miroslav Zetek

Faculty of Mechanical Engineering, Department of Machining Technology, University of West Bohemia, Univerzitní 8, Pilsen 306 14, Czech Republic. E-mail: farskyj@rti.zcu.cz, baksa@rti.zcu.cz, mzetek@rti.zcu.cz

Grinding is one of the basic finishing operations which can be used for parts made from different materials where high quality and surface accuracy is required. One of these materials is maraging steel 1.2709, which is used for the test samples for tensile testing. In this case, it is very important to achieve good surface quality. Wear of a grinding wheel is best expressed as G-ratio which shows us if the grinding parameters are selected correctly. This article deals with the influence of grinding conditions and grinding wheels on surface roughness and wear of the grinding wheels when grinding tool steel VACO 180 on a 5-axis grinding machine. The experiment was designed to investigate the influence of changes in cutting speed, depth of cut and using two different grinding wheels for these two values. At the end of the article the results from the experiment are summarized and compared.

Keywords: Grinding, Steel, SiC, Roughness, Wearing, G-ratio

\section{Introduction}

Maraging steel 1.2709 is used for mechanically stressed components. For these are usually selected materials which have a high strength limit, yield strength and also have high toughness and low sensitivity to notching, all at elevated temperatures. The chemical composition and mechanical properties of this material are shown in tables (Tab. 1, Tab. 2). Moreover, this steel is equivalent to steel marked DIN X3NiCoMo 1895 but mainly to steel MS1 from EOS which is used for printing metal components by DMLS technology. That is why this steel is used for the test bars for testing material characteristics and their comparison between conventional and additive manufacturing. These bars must have perfect surface roughness because even a small notch can influence the results. Therefore, it is necessary to use a finishing operation for making these test bars. Grinding is usually used for finishing these surfaces, because the combination of the grinding wheel and the grinding conditions can achieve the desired surface quality. [1], [2]

Tab. 1The chemical composition of maraging steel 1.2709 [2]

\begin{tabular}{|c|c|c|c|c|c|}
\hline C & Co & Mo & $\mathrm{Ni}$ & Ti & Others \\
\hline$<0.03 \%$ & $9.0 \%$ & $5.0 \%$ & $18.5 \%$ & $0.75 \%$ & $\mathrm{Al}, \mathrm{B}, \mathrm{Zr}$ \\
\hline
\end{tabular}

Tab. 2The mechanical properties of maraging steel 1.2709 [2]

\begin{tabular}{c|c|c|c|c|c|}
\hline Yield strength & Tensile strength & Ductility & Contraction & Notch toughness & Hardness \\
\hline $640 \mathrm{MPa}$ & $930-1130 \mathrm{MPa}$ & $12 \%$ & $60 \%$ & $55 \mathrm{~J}$ & $350 \mathrm{HV}$ \\
\hline
\end{tabular}

Grinding is one of the basic operations which is used for finishing surfaces. The quality of the surface after grinding is given by the grinding wheel, grinding conditions, liquid, etc. The composition of the grinding wheel and grinding conditions are very influential on the surface quality. If these two things are selected incorrectly, then we do not achieve the required quality. The theory shows us that using a silicon carbide grinding wheel is right for this material. Further specification depends on the method used and the requirements. Except for selecting the grinding wheels, we need to select the right grinding condition. Because grinding conditions influence the grinding process in many ways, from the surface parameters of the components to the grinding wheels. Fig. 1 shows the influence of grinding speed on other grinding parameters. As you can see, increasing grinding speed increases production but also can reduce wear, grinding forces and also improve surface roughness. [3], [4], [5], [6]

Wear of grinding wheels is very problematic and it is necessary to monitor it because the size of wear can increase errors in accuracy. Simultaneously, the size of wear influences the productivity of grinding. The size of the wear is usually measured as the change of the diameter of the grinding wheel. But this number only tells us how much change of the diameter has oc- 
curred. A more informative value for this is the G-ratio which tells us the productivity of the grinding wheel, because it is given by the ratio between the volume of material removed and the volume of wheel wear. This value tells us more information because we can see immediately if the selected grinding wheel or grinding conditions are sufficient or not. And also we can compare it with the surface roughness. [7], [8]

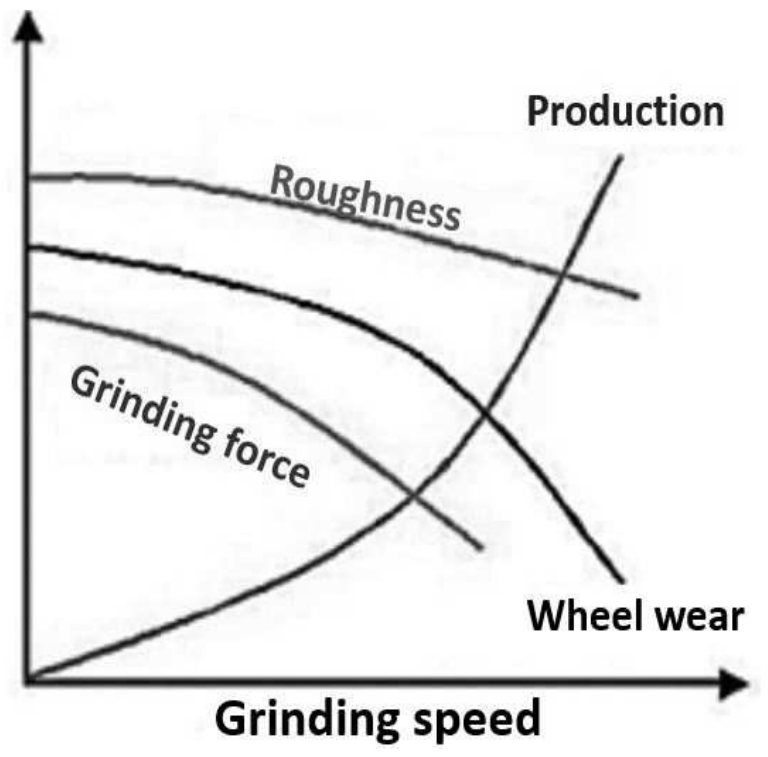

Fig. 1 Influence of grinding speed on grinding parameters [10]

This article is focused on fundamental research of the influence of grinding condition and $\mathrm{SiC}$ grinding wheels on surface quality. Also, during the experiments we monitored the wear of the grinding wheels. This wear was recalculated to the G-ratio, which is the volume of material removed divided by the volume of grinding wheel wear. These two monitored parameters can predict the results of grinding. In this case, this article is focused on the roughness after changing the grinding speed and depth of cut on two different $\mathrm{SiC}$ grinding wheels. The theory shows us that the grinding speed and depth of cut are two grinding conditions which can influence the roughness and also the wearing of grinding wheels. [9]

\section{Experiment}

The experiments were designed for grinding the test bars, which were $180 \times 36 \times 5.2 \mathrm{~mm}$ (length $\mathrm{x}$ height $\mathrm{x}$ width). The grinder ANCA MX7 was used for grinding these sticks. A Zoller Genius 3s was used to measure the wear of the grinding wheels and it scans the profile curve of the surface on the wheels. These profiles were used to measure the size of wear after each grinding. The roughness was measured on a IFM G4 scanning optical microscope. Apart from the basic roughness parameters, it is possible to determine the Abbot curve.

The main aim of these experiments was to verify the grinding wheels and the grinding conditions. The grinding wheels are shown in Tab. 3 with specification and their designation for these experiments. Tab. 4 shows the grinding conditions used in each of the experiments. It shows only the grinding conditions which were changed during the experiments. The other parameters were constant. These were the feed rate of $200 \mathrm{~mm} \cdot \mathrm{min}^{-1}$ and the axial step of $5.2 \mathrm{~mm}$ which was given by the width of the test bar. Experimental grinding was designed so that the grinding length was $540 \mathrm{~mm}$. Therefore, it was necessary to grind 3 paths in each experiment. Down grinding with coolant was used for all experiments. The strategy with a coolant supply system is shown in Fig. 2.

Tab. 3 Specification of grinding wheels used for experiments

\begin{tabular}{|c|c|c|c|c|c|c|c|}
\hline $\begin{array}{l}\text { Designa- } \\
\text { tion }\end{array}$ & Specification & Shape & $\begin{array}{l}\text { Dimen- } \\
\text { sion }\end{array}$ & Type of grain & $\begin{array}{l}\text { Grain } \\
\text { size } \\
\text { [FEPA] }\end{array}$ & $\begin{array}{l}\text { Bon- } \\
\text { ding }\end{array}$ & Hardness \\
\hline $\mathrm{SiC}-\mathbf{A}$ & $\begin{array}{c}49 \mathrm{C} 240 \mathrm{~J} \\
40\end{array}$ & 1A1 & $100 \times 10$ & $\begin{array}{l}\text { Silicon carbide } \\
\text { green }\end{array}$ & $\begin{array}{l}240 \text { (very } \\
\text { soft) }\end{array}$ & Ceramic & Soft \\
\hline $\mathrm{SiC}-\mathrm{B}$ & $\begin{array}{c}49 \mathrm{C} 80 \mathrm{~K} 9 \mathrm{~V} \\
40\end{array}$ & 1A1 & $100 \times 10$ & $\begin{array}{l}\text { Silicon carbide } \\
\text { green }\end{array}$ & 80 (soft) & Ceramic & Medium \\
\hline
\end{tabular}

Tab. 4 Specification of grinding condition for experiments

\begin{tabular}{|c|c|c|c|c|c|c|c|c|}
\hline $\begin{array}{l}\text { Designa- } \\
\text { tion }\end{array}$ & $\mathrm{v}_{\mathrm{c}}\left[\mathrm{m} \cdot \mathrm{s}^{-1}\right]$ & $\mathrm{a}_{\mathrm{e}}[\mathrm{mm}]$ & $\begin{array}{l}\text { Designa- } \\
\text { tion }\end{array}$ & $\mathrm{v}_{\mathrm{c}}\left[\mathrm{m} \cdot \mathrm{s}^{-1}\right]$ & $\mathrm{a}_{\mathrm{e}}[\mathrm{mm}]$ & $\begin{array}{l}\text { Designa- } \\
\text { tion }\end{array}$ & $\mathrm{v}_{\mathrm{c}}\left[\mathrm{m} \cdot \mathrm{s}^{-1}\right]$ & $\mathrm{a}_{\mathrm{e}}[\mathrm{mm}]$ \\
\hline Exp01 & 25 & 0.025 & Exp04 & 25 & 0.05 & Exp07 & 25 & 0.1 \\
\hline Exp02 & 30 & 0.025 & Exp05 & 30 & 0.05 & Exp08 & 30 & 0.1 \\
\hline Exp03 & 35 & 0.025 & Exp06 & 35 & 0.05 & Exp09 & 35 & 0.1 \\
\hline
\end{tabular}




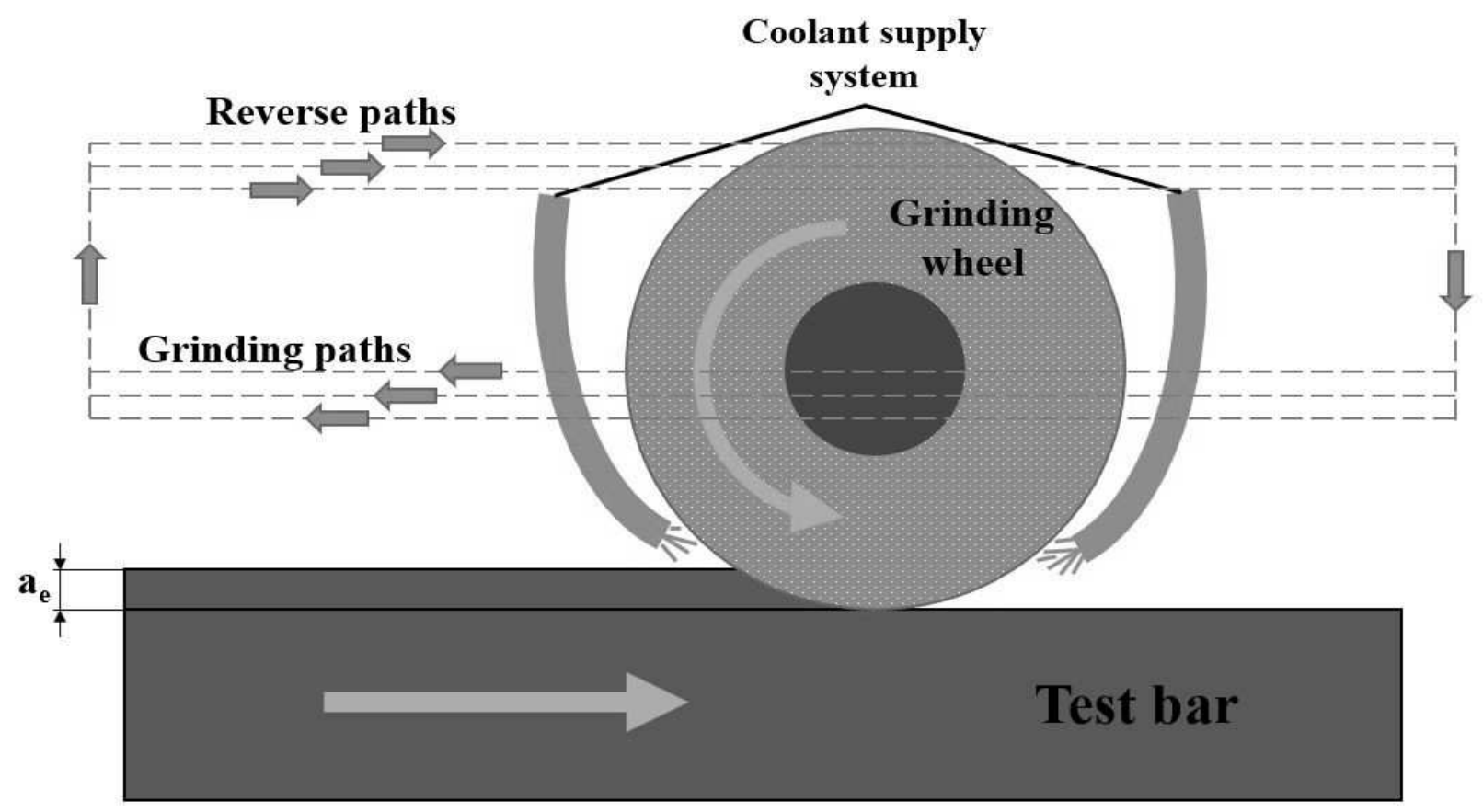

Fig. 2 Grinding strategy

\section{Results}

Surface roughness was measured in three sections perpendicular to the toolpath on an IFM G4 opticalscanning microscope. The values measured in individual experiments were added to the graphs which compare the values and the grinding wheels. Also, the graphs show the G-ratio for each experiment. Surface roughness and G-ratio are important because their combination shows us if the grinding conditions are suitable or not.

The results after grinding with the first grinding wheel are shown in Fig. 3. The value of surface roughness increases with higher grinding speed. This tells us that the best option for grinding speed is $25 \mathrm{~m} . \mathrm{s}^{-1}$ with this combination of the other grinding parameters. Also, we can saw the depth of cut influence the surface roughness. Similar values of surface roughness were reached in the depth of cut 0.025 and $0.05 \mathrm{~mm}$. In the last depth of cut was reach a big difference of surface roughness, compared with the first two, which could have been caused by overfilling the grinding wheel. The best value of surface roughness was achieved in combination grinding speed $25 \mathrm{~m} . \mathrm{s}^{-1}$ with a depth of cut of $0.025 \mathrm{~mm}$.

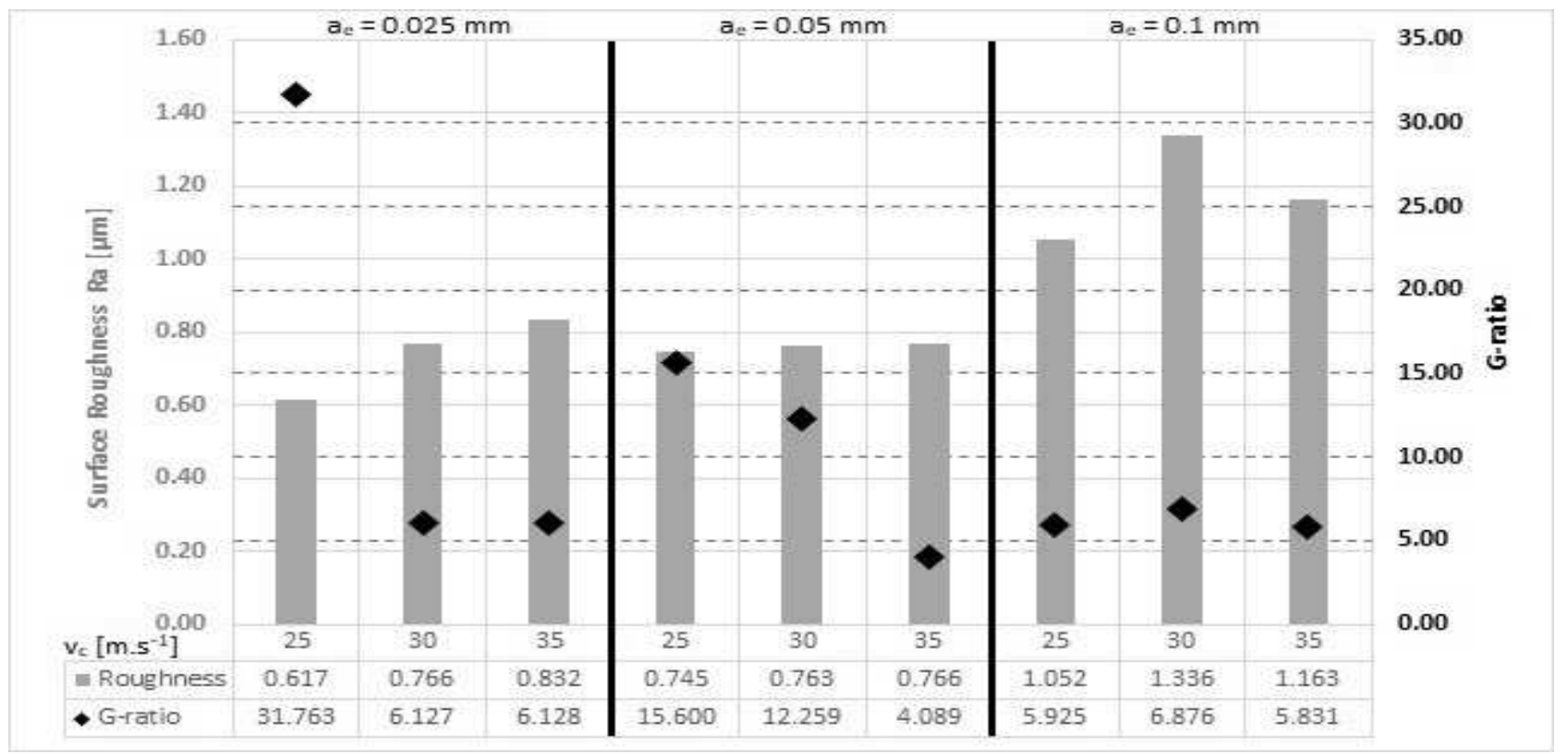

Fig. 3 Graph of roughness and G-ratio for grinding wheel SiC - A 
The value of G-ratio shows us which are the best parameters for effective grinding this material with this grinding wheel. In the depth of cut $0.1 \mathrm{~mm}$ we can saw the value of G-ratio is smallest, so in this case, the wearing of the grinding wheel is biggest. This told us the effectivity of this parameters is bad. On the depth of cut $0.05 \mathrm{~mm}$ we can see when the grinding speed rises then the G-ratio fell. On the smallest depth of cut $0.025 \mathrm{~mm}$ was reached the highest G-ratio, but only for grinding speed $25 \mathrm{~m} . \mathrm{s}^{-1}$. For grinding speed 30 and $35 \mathrm{~m} . \mathrm{s}^{-1}$ the G-ratio was fell down very down. This told us the effective grinding conditions for this case are a combination of grinding speed $25 \mathrm{~m} . \mathrm{s}^{-1}$ with the depth of cut $0.025 \mathrm{~mm}$ and grinding speed 25 and $30 \mathrm{~m} . \mathrm{s}^{-1}$ with the depth of cut $0.05 \mathrm{~mm}$.

The results of surface roughness and G-ratio from the grinding wheel B are shown in Fig. 4. In this case, the surface was burned after grinding with parameters ae $=0.1 \mathrm{~mm}$. Therefore, the results are not shown with these parameters in the graph. The values of surface roughness are changed very little when grinding speed increases for this grinding wheel. Nevertheless, with the bigger depth of cut the size of surface roughness fell approximately by $0.3 \mu \mathrm{m}$.

The value of G-ratio for this grinding wheel is very changeable. This was caused by selecting the bad combination between the grinding speed, feed rate, and amount of remove material in one layer. And at first glance, we can see which combination of parameters was unsuitable for use. In this case, there are 3 sets of parameters which were suitable for use. It was in the combination the grinding speed $30 \mathrm{~m} . \mathrm{s}^{-1}$ with a depth of cut $0.025 \mathrm{~mm}$ and for grinding speed 25 and $30 \mathrm{~m} . \mathrm{s}^{-}$ 1 and depth of cut $0.05 \mathrm{~mm}$.

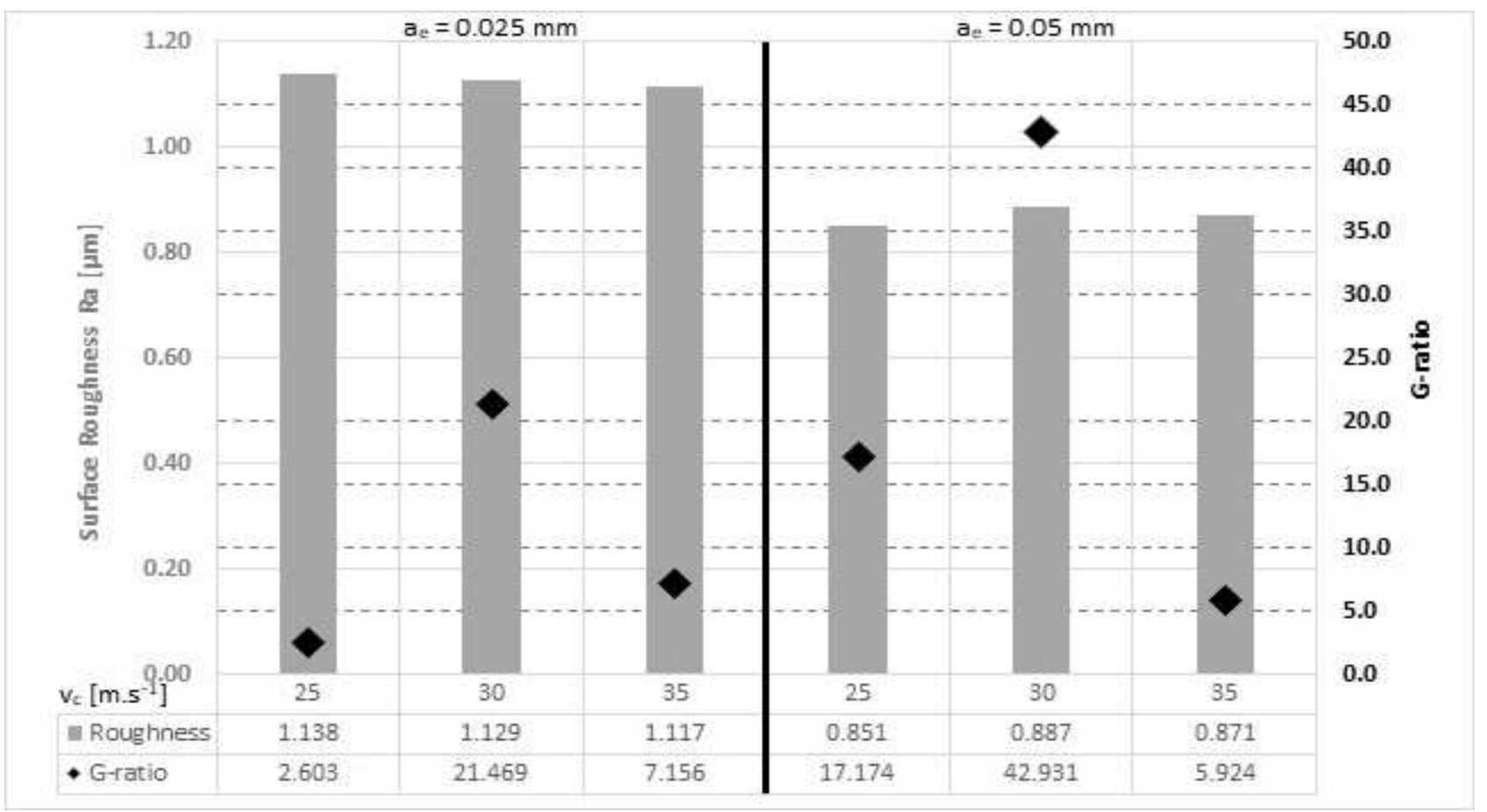

Fig. 4 Graph of roughness and G-ratio for grinding wheel SiC - B

When we compare the results from grinding wheel $A$ and $B$, we see grinding wheel $A$ has a better value of surface roughness by $0.2 \mu \mathrm{m}$ than the best value of roughness for grinding wheel $\mathrm{B}$. When we compare the values of roughness with the same grinding parameters, then we see big differences. This is caused by the different grain sizes and hardnesses of the grinding wheels. The better value of G-ratio was achieved the grinding wheel $\mathrm{B}$. This means we remove more material with the same value of wear as grinding wheel A. Also, this value was achieved with a two times higher value of depth of cut which means the time for removing the material is halved. But in both cases, the values are very changeable. This told us there was selected the wrong combination between grinding speed, feed rate, and amount of removing material in the cases where the G-ratio was very small.

\section{Conclusion}

Surface roughness is one of the most important parameters for test specimens. This parameter can influence testing because bad surface roughness can be a concentrator of tension. Wear of the grinding wheel was also monitored. This was recalculated as the Gratio, which provides us with more information about the productivity of the grinding conditions.

We can draw several conclusions from the results of this experiment. Firstly, we can say grinding wheel A achieved better surface roughness than B. Also, with these grinding conditions we achieved the best value of G-ratio for this grinding wheel. Grinding 
wheel B achieves worse surface roughness than A, but the G-ratio for this grinding wheel was higher. This G-ratio was also reached with a bigger value of depth of cut. This showed us that grinding wheel B can remove more material in less time. So, we can say grinding wheel $A$ is better for finishing operations and grinding wheel B is better for roughing operations. But only a few experiments with different grinding conditions were performed, and we may gain better results if we reduce the grinding speed or change the feed rate.

Further research will involve changing the grinding speed and values of feed rate and test them on the same grinding wheels, because from these results we see the surface roughness start to increase when increasing the grinding speed and the theory says the opposite.

\section{Acknowledgement}

This paper was supported by the Internal Grant Agency of the University of West Bohemia, project No. SGS-2019-008. Research and Development for Innovation in the Field of Manufacturing Technology - Machining Technology III.

\section{References}

[1] KLOCKE, F. (2009). Manufacturing Processes 2: Grinding, Honing, Lapping. Springer Science \& Business Media, 2009.

[2] Maraging steel - VACO 180, Bolzano. [Online]. Available: https://www.bolzano.cz/assets/files/materialove_listy/Vaco\%20180(1).pdf. [Accessed: 25-Sep-2019].
[3] M. NOVAK, H. KASUGA, and H. OHMORI (2019). Differences at the surface roughness by the ELID and grinding technology, Manuf. Technol., vol. 13, no. 2, pp. 210-215, 2013.

[4] A. AGRAWAL, S. W. HASHMI, Y. RAO, AND A. GARG (2015). Evaluation of Surface Roughness and Tensile Strength of Base Metal Alloys Used for Crown and Bridge on Recasting (Recycling), J. Clin. Diagn. Res. JCDR, vol. 9, no. 7, pp. ZC01-ZC04, Jul. 2015.

[5] NOVAK, M., NAPRSTKVA, N. (2015). Grinding of the alloy INCONEL 718 and final roughness of the surface and material share, Manuf. Technol., vol. 15, no. 6, pp. 1015-1023, 2015.

[6] NOVAK, M. (2011). Surface quality of hardened steels after grinding, Manuf. Technol., vol. 11, pp. 55-59, 2011.

[7] NOVAK, M., DOLEZAL, R. (2012). G-Ratio in hardened steel grinding with different coolants, Manuf. Technol., vol. 12, no. 13, 2012.

[8] W. B. Rowe, 'Chapter 5 - Wheel Contact Effects', in Principles of Modern Grinding Technology, W. B. Rowe, Ed. Boston: William Andrew Publishing, 2009, pp. 79-93.

[9] NOVAK, M. (2012). Surfaces with high precision of roughness after grinding, Manuf. Technol., vol. 12, pp. 66-70, 2012.

[10] E. JANNONE DA SILVA, M. BIFFI, AND J. FERNANDO GOMES DE OLIVEIRA, 'The Development of an Open Architecture Control System for CBN High Speed Grinding', J. Braz: Soc. Mech. Sci. Eng., vol. 26, 2004. 